American Journal of

Health, Medicine and Nursing Practice (AJHMN)

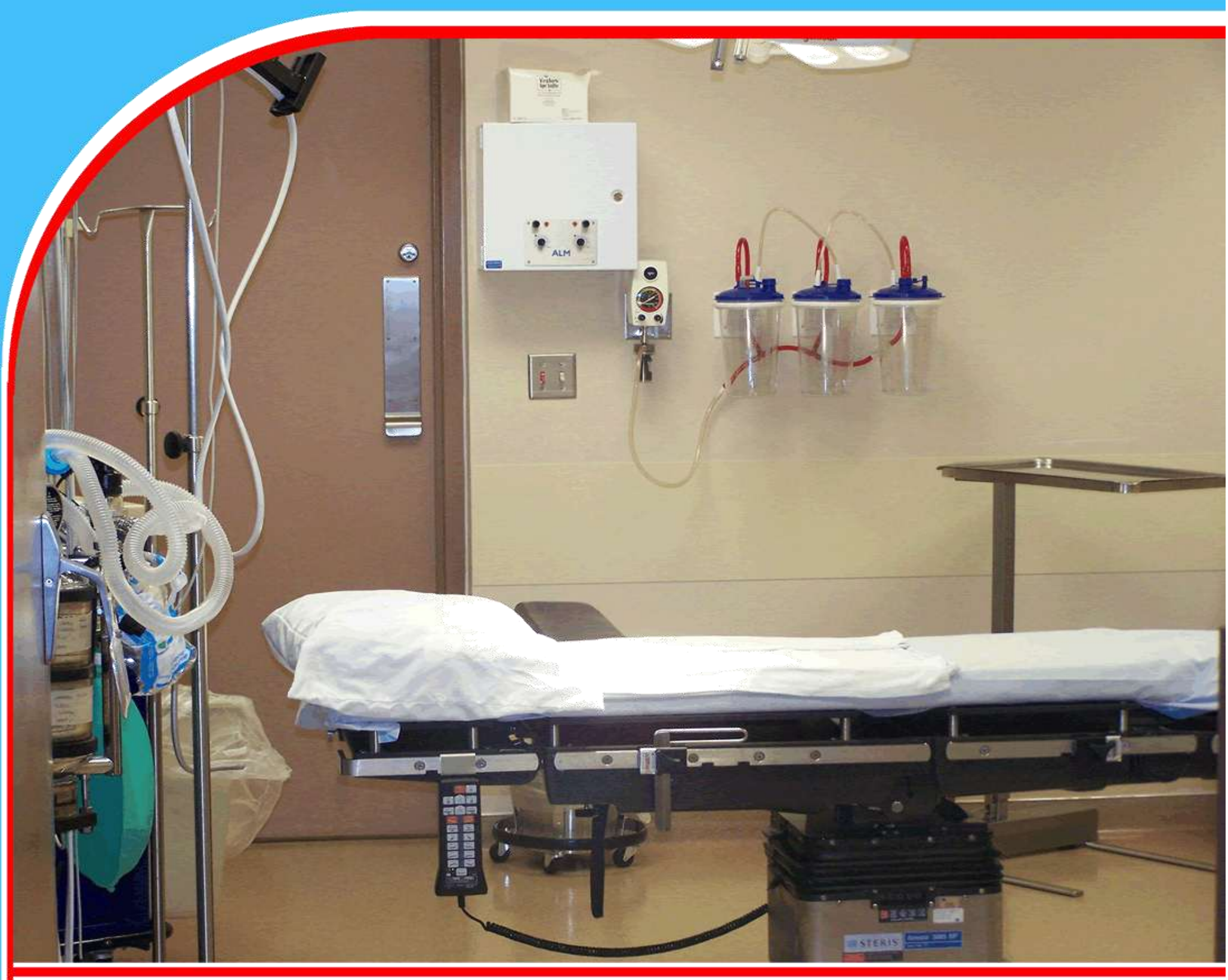

PREVELANCE OF NON-SPECIFIC NECK PAIN AMONG SURGEONS IN DIFFERENT HOSPITALS OF LAHORE.

Amirah Zafar Saad Kamal Akhtar Umar Sadiq Sobia

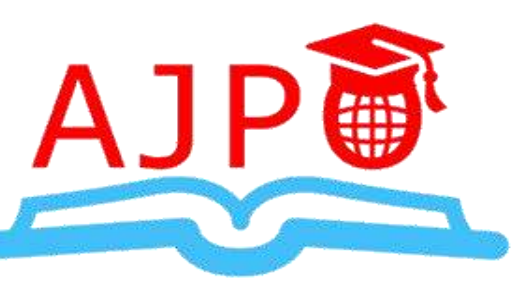


American Journal of Health, Medicine and Nursing Practice

ISSN 2520-4017 (Online)

Vol.6, Issue 2, pp $42-47,2021$

www.ajpojournals.org

\title{
PREVELANCE OF NON-SPECIFIC NECK PAIN AMONG SURGEONS IN DIFFERENT HOSPITALS OF LAHORE
}

\author{
Amirah Zafar ${ }^{1}$ \\ Senior Lecturer \\ CMH Medical College \& IOD Lahore. \\ Corresponding Author's Email: amirahzafar89@gmail.com \\ Saad Kamal Akhtar ${ }^{2}$ \\ Email: skak86@gmail.com \\ Multan Institute of Health Sciences, Multan. \\ Umar Sadiq ${ }^{3}$ \\ Email: umarsadiq89@yahoo.com \\ Assistant Professor \\ CMH Medical College \& IOD Lahore. \\ Sobia ${ }^{4}$ \\ Email: sobisadiq910@gmail.com \\ DOW University
}

\begin{abstract}
Objective: The objective of the study was to determine the prevalence of non-specific neck pain among Surgeons in different hospitals of Lahore and developed some guidelines to reduce the occupational hazards.

Materials and Methods: It was a cross-sectional study. Non-Probability Convenient sampling technique was used. Data was collected from surgeons working in tertiary care hospitals of Lahore Inclusion criteria included Surgeons ( 25 years or above), both genders selected and Neck pain in cervical region, surgery of consecutive 2- 3 hours or more. Exclusion criteria included age under 25 years, any neurological disorders, cerebrovascular insufficiency, Past history of Infection and Malignancy, any Structural disorders and Trauma. Data was collected by questionnaire form set on paper.

Results: Non-specific neck pain has positive statistically significant association with "Starting of Neck Pain Surgical Day", "Starting of Neck Pain Post-Surgical Day", "Worsening of Neck Pain Surgical Day" and "Worsening of Neck Pain Post-Surgical Day

Conclusion: It concluded that the surgeons are not getting neck pain due to the surgical activities but it may worsen by their surgical activities of consecutive 3 hours if they already have some neck-related problems.

Recommendations: Prolong working hours should be reduced which ultimately affect their ergonomics and posture of neck. By reducing consecutive hours of surgery neck pain can be minimized. Surgeons should be trained about their postural alignment while performing surgeries as to prevent maximum stress on neck musculature to avoid neck pain.
\end{abstract}

Key words: Non-Specific, Prevalence, Neck pain, Hospitals. 
American Journal of Health, Medicine and Nursing Practice

ISSN 2520-4017 (Online)

Vol.6, Issue 2, pp $42-47,2021$

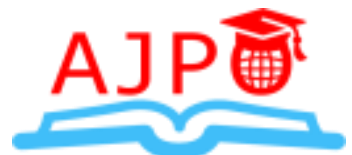

WWW.ajpojournals.org

\section{INTRODUCTION}

Neck pain is a common problem which includes non-specific neck associated disorders. Symptoms aggravates with time and with physical activity. Idiopathic neck pain, where no abnormal anatomical structures are present that causes pain, it is known as non-specific neck pain. Nonspecific neck pain is defined as simple neck pain having no specific underlying disease that causes the pain. Symptoms may be severe or mild with physical activity and over time. It may be acute, sub-acute or chronic neck pain, where no abnormal anatomic structure; as cause of pain, can be identified, is non-specific neck pain [1-2]. The epidemiology of neck pain are at some points in life, two-third of population will suffered from neck pain, women are more affected than men, prevalence rises with age in both sexes and in age group between 50-59 years, people in which neck pain becomes chronic is about $10 \%$ Non-specific neck pain can be diagnosed on clinical trials alone, the red flag proposed are based on best quality guideline.[3]. Non-Specific Neck Pain is considered as a painful and an unpleasant experience (both sensory and emotional) in neck region.[3] Not only is neck pain one of the most frequent musculoskeletal complaints, it is second only to low back pain in terms of cost and prevalence. Neck pain is not just a personal health problem in terms of pain and the negative influence it can have on a person's quality of life, but the high prevalence of the disorder also makes it a major public health problem in terms of overall well-being, cost of work absence and medical expenses. In Hospitals, Surgeons are usually at high risk of non-specific neck pain due to limited area, mechanical stress, weak muscles, and stressful positions to achieve better access. [4] This study aims to provide a systemic review of scientific literature on prevalence of acute and chronic non-specific neck pain. The objective of this literature is to propose evidence-based key massages to diagnose who suffer from non-specific neck pain

OBJECTIVE: The objective of the study was to determine the prevalence of non-specific neck pain among Surgeons in different hospitals of Lahore and developed some guidelines to reduce the occupational hazards

\section{LITERATURE REVIEW}

Of neck pain sufferers, 14-19\% may develop chronic pain [5] and approximately $19 \%$ of the population may suffer from chronic neck pain at any given time [6]. Most neck pain is thought to result from irritation or injury to part of the neck, commonly caused by poor posture, mechanical stress, and changes to the normal condition of the joints and discs over time. Chronic neck pain, as with other chronic conditions, is generally considered to be of multicausal etiology and does not lend itself to simple diagnosis (Mason, 2008). In the majority of cases of chronic neck pain there is little evidence of specific pathology or cause, and neck pain is classed as non-specific.[7]

Melan et al conducted research on prevalence of MSK among dentist. Analysis revealed that there is a correlation between MSD and neck pain. MSD was frequently reported dental hygienists in Neck $(85 \%)$, shoulder $(70 \%)$, low back $(68 \%)$. Of these reporting pain, two third reported that pain lasted for longer than four days especially in neck regions [8]. Overall, this study suggested that neck pain due to MSD is reasonably common problem in Australian dental hygienists. One study conducted in 2007 among dental surgeons who practiced 7-11 years and concluded that $70.59 \%$ subjects were suffering from backache and $23.53 \%$ suffered from neck pain. 
Monique conducted a study in 2013 on "osteopathic treatment on nonspecific neck pain and disability".21 subjects were included with chronic non-specific neck pain. Improvement was seen after 3 weeks of treatment in neck disability index. Self-reported pain and disability were reduced after osteopathic treatment.[9]

\section{MATERIALS AND METHODS}

It was a cross-sectional study. Data was collected from Jinnah hospital Lahore and completed within six months. Non-Probability Convenient sampling technique was used to collect the data due to time limitation. Inclusion criteria included Surgeons (25 years or above), both genders selected and Neck pain in cervical region with radiating or referred pain in nuchal muscles, the occiput. Exclusion criteria included age under 25 years, having signs and symptoms of any neurological disorders, cerebrovascular insufficiency, Past history of Specific sign of Infection and Malignancy, Red flag signs and Structural disorders and Trauma. Data was collected by questionnaire. Questionnaire was consisting of self-designed questionnaires. Before data collection identity of author and the research project and its purpose was delivered verbally among participants and written consent form was taken. The data was analyzed using SPSS.

\section{RESULTS:}

Data was obtained from the Surgeons working in tertiary care hospitals of Lahore and total number of 62 responses was collected.

Respondents of $40.3 \%$ were from age group 31-35 years. While $38.7 \%$ were from age group of 25-30 years.

In total respondents $29 \%$ were General Surgeons, $24.2 \%$ were Ophthalmologists, and $14.5 \%$ were Urologists, $11.3 \%, 8.1 \%, 1.6 \%$ were Neurosurgeons, orthopedic surgeons, gynecologists and ENT surgeons. 
American Journal of Health, Medicine and Nursing Practice

ISSN 2520-4017 (Online)

Vol.6, Issue 2, pp 42 -47, 2021

www.ajpojournals.org

Table \# 1: Correlations of variables with Intensity of neck pain.

\begin{tabular}{|ll|r|}
\hline Neck Pain Presence & Pearson Correlation & $.682^{* *}$ \\
& Sig. (1-tailed) & .000 \\
& $\mathrm{~N}$ & 62 \\
\hline Starting of Neck Pain Daily & Pearson Correlation & .091 \\
& Sig. (1-tailed) & .242 \\
& $\mathrm{~N}$ & 62 \\
\hline Starting of Neck Pain & Pearson Correlation & $.299^{* *}$ \\
Surgical Day & Sig. (1-tailed) & .009 \\
& $\mathrm{~N}$ & 62 \\
\hline Starting of Neck Pain Post- & Pearson Correlation & $.255^{*}$ \\
Surgical Day & Sig. (1-tailed) & .023 \\
& $\mathrm{~N}$ & 62 \\
\hline Worsening of Neck Pain & Pearson Correlation & $.364^{* *}$ \\
Daily & Sig. (1-tailed) & .002 \\
& $\mathrm{~N}$ & 62 \\
\hline Worsening of Neck Pain & Pearson Correlation & $.685^{* *}$ \\
Surgical Day & Sig. (1-tailed) & .000 \\
& $\mathrm{~N}$ & 62 \\
\hline Worsening of Neck Pain & Pearson Correlation & $.272^{*}$ \\
Post-Surgical Day & Sig. (1-tailed) & .016 \\
& $\mathrm{~N}$ & 62 \\
\hline Hours Wasted due to Pain / & Pearson Correlation & .193 \\
Day & Sig. (1-tailed) & .067 \\
& $\mathrm{~N}$ & 62 \\
\hline
\end{tabular}

**. Correlation is significant at the 0.01 level (1-tailed).

*. Correlation is significant at the 0.05 level (1-tailed) 
American Journal of Health, Medicine and Nursing Practice

ISSN 2520-4017 (Online)

Vol.6, Issue 2, pp $42-47,2021$

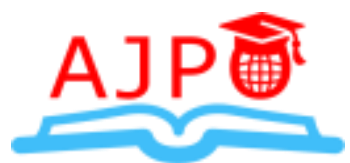

www.ajpojournals.org

Table \# 2: Correlations of variables with presence of neck pain.

\begin{tabular}{|ll|c|}
\hline Working Days / Week & Pearson Correlation & $-.224^{*}$ \\
& Sig. (1-tailed) & .040 \\
& $\mathrm{~N}$ & 62 \\
\hline Working Hours / Day & Pearson Correlation & .022 \\
& Sig. (1-tailed) & .431 \\
& $\mathrm{~N}$ & 62 \\
\hline Operation Theater Days / & Pearson Correlation & -.053 \\
Week & Sig. (1-tailed) & .340 \\
& $\mathrm{~N}$ & 62 \\
\hline Theater Hours / Theater Day Pearson Correlation & -.071 \\
& Sig. (1-tailed) & .292 \\
& $\mathrm{~N}$ & 62 \\
\hline
\end{tabular}

\section{DISCUSSION}

Borghouts et. al conducted research on neck results based on the Intego non-specific neck pain is in top 20 of most frequent diagnoses in 2006. The estimated incidence of neck syndromes (including non-specific neck pain) was $24.84 \%$ for the contact population in yearly period of 2006. Women suffered more than men from this symptom (31.48 \%o, 7 th reason for contact) than men (18.43\%, 9th reason for contact) [10]. On the contrary this study was conducted among surgeons on non-specific neck pain. It showed that neck pain has statistically significant association with starting of neck pain with surgical days and worsening of neck pain with surgical days. But they don't get pain due to surgical activity there might be some other issues or causes which aggravate the pain. Cote p. et. al conducted a research of 8356 subjects in which $72 \%$ respondants are observed in study. About $43 \%$ (48\% of women and 38\% of men) of the population reported neck pain. Chronic neck pain was more common (22\%) in women than in (16\%) men.[11] More than one fourth of the cases with chronic symptoms had a history of neck or head trauma and one third of these had a whiplash injury whereas my study showed that neck pain may get worsen by surgical activities among surgeon if there is some underlying cause rather than any surgical activities aggravate it.

\section{CONCLUSION}

It can be concluded that the surgeons are not getting neck pain due to the surgical activities but it may worsen by their surgical activities of consecutive 3 hours or more if they already have neck related issues.

\section{RECOMMENDATIONS}

1. Prolong working hours should be reduced which ultimately affect their ergonomics and posture of neck.

2. By reducing consecutive hours of surgery neck pain can be minimized.

3. Surgeons should be trained about their postural alignment while performing surgeries as to prevent maximum stress on neck musculature to avoid neck pain. 
American Journal of Health, Medicine and Nursing Practice

ISSN 2520-4017 (Online)

Vol.6, Issue 2, pp $42-47,2021$

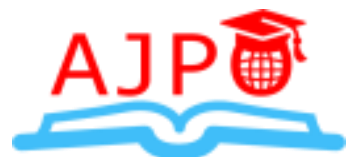

www.ajpojournals.org

\section{LIMITATIONS}

Following limitations were found in the research project.

Poor response: Doctors are not only the worst patients but they are also the worst respondents too. Many doctors negate the neck pain and refuse to fill the questionnaire. Senior doctors also made excuse due to their busy schedule. This made it tough to gather the responses.

Female' hesitation: Female doctors mostly hesitated to fill the questionnaire. Hence, fewer responses are gathered from them.

Time constrains: Shortage of time was also the limitation in the data collection procedure.

\section{REFERENCES}

1. Gray H, Lewis W. Anatomy of the human body

2. Binder A. The diagnosis and treatment of nonspecific neck pain and whiplash. Eura.Medicophys. 2007;43(1):79-89.

3. Tsakitzidis G, Remmen R, Peremans L, Van Royen P, Duchesnes C, Paulus D, et al. Nonspecific neck pain: diagnosis and treatment. KCE reports 119C. 2009.

4. [Internet]. 2015 [cited 9 May 2015]. Available from: http://www.cks.nhs.uk/neck_pain_non_specific

5. Cathrin, Gs., Krysia Dziedzic., Jackie Waterfield., Julius Sim.(2009) Effectiveness of specific neck stabilization exercises or a general neck exercise program for chronic neck disorders: a randomized controlled trial. J Rheumatol Feb;36(2):390-7.

6. Chopra, S. and Pandey, S. (2007). Occupational hazards among dental surgeons. Medical Journal Armed Forces India, 63(1), pp.23-25.

7. Hayes, M., Smith, D. and Taylor, J. (2013). Musculoskeletal disorders and symptom severity among Australian dental hygienists. BMC Research Notes, 6(1), p.250.

8. Hoving JL, Koes BW, de Vet HCW, van der Windt DAWM, Assendelft WJJ, vanMameren $\mathrm{H}$, et al. Manual therapy, physical therapy, or continued care by a general practitioner for patients with neck pain. Ann Intern Med 2002; 136:713-22.

9. Hayes, M., Smith, D. and Taylor, J. (2013). Musculoskeletal disorders and symptom severity among Australian dental hygienists. BMC Research Notes, 6(1), p. 250.

10. Borghouts J, Koes B, Vondeling H et al (1996) Cost-of-illness of neck pain in The Netherlands in 1996. Pain 80(3):629-636

11. Côté P, Hogg-Johnson S, Cassidy JD, et al. The association between neck pain intensity, physical functioning, depressive symptomatology and claim duration after whiplash. J Clin Epidemiol 2001; 54: 275-86. 